\title{
ETHANOLIC EXTRACT OF TUBTIM-CHUMPHAE RICE BRAN DECREASES INSULIN RESISTANCE AND INTRAHEPATIC FAT ACCUMULATION IN HIGH-FAT-HIGH-FRUCTOSE DIET FED RATS
}

\section{JIRAPRAPA PONGLONG ${ }^{1,2}$, LADDAWAN SENGGUNPRAI ${ }^{1}$, PANOT TUNGSUTJARIT ${ }^{1,2}$, RONNACHAI CHANGSRI $^{3}$, TUNVARAPORN PROONGKHONG ${ }^{3}$, PATCHAREEWAN PANNANGPETCH ${ }^{1,2 *}$}

${ }^{1}$ Department of Pharmacology, Faculty of Medicine, Khon Kaen University, Khon Kaen, Thailand. ${ }^{2}$ Cardiovascular Research Group, Khon Kaen University, Khon Kaen, Thailand. ${ }^{3}$ Chumphae Rice Research Centre, Khon Kaen, Thailand.

Email: patc_pan@kku.ac.th

Received: 31 October 2018, Revised and Accepted: 14 December 2018

\section{ABSTRACT}

Objective: Tubtim-chumphae rice is hybrid Thai rice with a red pericarp. This study was aimed to investigate the effect of Tubtim-chumphae rice bran on insulin resistance and intrahepatic fat accumulation in high-fat-high-fructose diet (HFFD) fed rats.

Methods: Ethanolic extract of rice bran (ERB) was prepared using a 50\% ethanol-water. Male Sprague-Dawley rats were fed HFFD $(40 \%$ lard, $20 \%$ fructose) for 10 weeks, followed by concomitant administrations of distilled water or ERB at 250 or $500 \mathrm{mg} / \mathrm{kg} / \mathrm{day}$ or pioglitazone at $10 \mathrm{mg} / \mathrm{kg} / \mathrm{day}$ for a further 4 weeks in treated groups. Normal control rats were fed normal chow and distilled water. At the end of all treatments, fasting blood glucose (FBG), an oral glucose tolerance test (OGTT), serum insulin levels, lipid profiles, and liver fat contents were measured. Liver histological and peroxisome proliferator-activated receptor- $\alpha$ (PPAR- $\alpha$ ) gene expression examinations were performed.

Results: At week 14, control HFFD rats had significantly ( $<<0.05$ ) higher FBG, low-density lipoprotein cholesterol, triglycerides, and insulin secretions together with impaired OGTT as compared to normal control rats. These parameters indicated an insulin resistant and dyslipidemic condition in HFFD rats. ERB 250 and $500 \mathrm{mg} / \mathrm{kg}$ or pioglitazone $10 \mathrm{mg} / \mathrm{kg}$ significantly ameliorated all of these changes. HFFD also caused a significant increase in fat accumulation and a decrease in PPAR- $\alpha$ gene expression in the livers which were significantly decreased by ERB.

Conclusions: ERB decreases insulin resistance and intrahepatic fat accumulation possibly through increasing PPAR- $\alpha$ gene expression in HFFD rats. ERB might possibly be a neutraceutical for the metabolic syndrome patients.

Keywords: Insulin resistance, Metabolic syndrome, Rice bran, Type 2 Diabetes.

(c) 2019 The Authors. Published by Innovare Academic Sciences Pvt Ltd. This is an open access article under the CC BY license (http://creativecommons. org/licenses/by/4. 0/) DOI: http://dx.doi.org/10.22159/ajpcr.2019.v12i1.30545

\section{INTRODUCTION}

The metabolic syndrome is composed of several metabolic changes including insulin resistance, impaired glucose tolerance, dyslipidemia, and central obesity. These metabolic changes provoke a risk of major health problems such as cardiovascular disease, Type 2 diabetes (Type $2 \mathrm{DM}$ ), and nonalcoholic fatty liver disease (NAFLD) [1]. Insulin resistance is proposed to be the main etiology of metabolic changes [2]. Chronic and excessive intake of a high-calorie fat and sugar diet can cause insulin resistance and fat accumulation in the liver (steatosis) [3]. Intrahepatic fat accumulation is the early stage of NAFLD and is the result of a high-fat intake, de novo lipogenesis or released lipids from adipose tissue [4]. Fructose is a monosaccharide found in many fruits, vegetables, honey, and soft drinks. It has been shown that overconsumption of fructose can enhance the risk of insulin resistance because fructose is predominantly metabolized in the liver where it promotes de novo lipogenesis and very low-density lipoprotein (LDL) biogenesis, and eventually intrahepatic fat accumulation [5].

The general recommendations for treatment of metabolic disorders are lifestyle modifications, such as caloric restriction, healthy foods, increased physical activity, medicinal herbs or neutraceutical supplementations, and eventually pharmacological intervention [3]. Various types of rice (Oryza sativa) are widely cultivated around the world. Rice is not only a major source of energy but also a source of many bioactive compounds and especially antioxidants including phenolic compounds [6-8]. Rice bran, a byproduct of rice grain milling process, is also full of many valuable bioactive compounds such as Vitamin E, $\gamma$-oryzanol, and anthocyanins [9] with health beneficial effects in decreasing blood cholesterol and reducing the incidence of atherosclerotic disease [10]. Interestingly, we have previously shown that the hydrolysate of white rice bran could decrease blood glucose, decrease hyperinsulinemia, improve dyslipidemia, and decrease the expression levels of the proinflammatory genes tumor necrosis factor-alpha, Il-6, Nos2, and Mcp-1 in high-fat high-carbohydrateinduced metabolic syndrome rats [11]. Those results indicated that the hydrolysate of white rice bran increases insulin sensitivity and improves metabolic changes in metabolic syndrome.

Tubtim-chumphae rice, a Thai rice cultivar RD69 with a red pericarp, is a hybrid of white Jasmine rice and colored Sangyod rice. This hybrid rice has a high content of phenolic compounds, Vitamin E ( $\gamma$-tocopheral), and $\gamma$-oryzanol (www.Thairice.org). Thus, Tubtim-chumphae rice bran may be another source of nutraceuticals for persons with metabolic syndrome and also Type 2 D. However, it still lacks the experiment to prove the therapeutic effect of colored rice bran on insulin resistance and intrahepatic fat accumulation in insulin resistance animals. Therefore, the objective of this study was to investigate the effect of the ethanolic extract of Tubtim-chumphae rice bran on insulin resistance and intrahepatic fat accumulation as well as its molecular mechanism in high-fat-high-fructose diet (HFFD) induced insulin resistant rats.

\section{METHODS}

Chemicals

Pioglitazone (Piozone's ${ }^{\circledR}$, M\&H Manufacturing Co. Ltd. Thailand), Trizol reagent and Diethyl pyrocarbonate-treated water (Invitrogen, San Diego, California), iScript Reverse Transcription Supermix for RT-q polymerase 
chain reactions (PCR) and SsoFast EvaGreen Supermix with Low ROX (Bio-RAD, USA), Agarose (Vivantis Inc., USA), Rat/Mouse Insulin ELISA Kit (Millipore MA, USA), Reagent Kit for determinations of LDL, highdensity lipoprotein (HDL) and triglyceride (TG) (Wako Pure Chemical Industries, Ltd. Japan), Pentobarbital Sodium solution (Nembutal ${ }^{\circledR}$, Ceva animal health., LTD., Thailand), sterile water for injection (A.N.B. Laboratories Co., LTD., Thailand), and normal saline solution (Thai Nakorn Patana Co., LTD., Thailand) were used in this study.

\section{Rice bran material and extraction}

Tubtim-chumphae rice bran (hybrid Thai rice cultivar RD69) was kindly supplied by Chumphae Rice Research Center, Chumphae district, Khon Kaen Province, Thailand. Preparation of the ethanolic extract of Tubtimchumphae rice bran (ERB) was used as follows: To inactivate endogenous lipases, rice bran was heated at $121^{\circ} \mathrm{C}$ for $15 \mathrm{~min}$ and dried in a cabinet drier at $60^{\circ} \mathrm{C}$ for $5 \mathrm{~h}$. The oil component was squeezed out by a screw press. After that, the defatted rice bran powder $(200 \mathrm{~g})$ was soaked in $1 \mathrm{~L}$ of $50 \%$ ethanol for 1 day with continuous shaking and filtered through Whatman No. 1 filter paper. The filtrates from three soakings were pooled together, and the solvent was removed using a rotary evaporator under reduced pressure and $60^{\circ} \mathrm{C}$. The extract was dried by a freezedrying process. The percent yield of this procedure is 10.4. The obtained powder Tubtim-chumphae ERB was stored at $-20^{\circ} \mathrm{C}$ until used.

To characterize the extract, the type and amount of some phenolic compounds were analyzed using a reverse-phase column and a ultraviolet-vis diode array detector high-performance liquid chromatography-diode-array detection (HPLC-DAD)-based assay [12].

\section{Animal and experimental groups}

Male Sprague-Dawley rats (230-250 g body weight) were purchased from the Nomura Siam International Co., Ltd, Bangkok, Thailand. Rats were housed in the Northeast Laboratory Animal Center and were maintained at $12 \mathrm{~h}$ of light/dark cycles at $25 \pm 1^{\circ} \mathrm{C}$, and fed with a standard chow diet (Perfect Companion Group Co. Ltd., Thailand) and drinking distilled water. Only the animals that were the induced insulin resistance group were fed a HFFD (HFFD of $40 \%$ lard and $20 \%$ fructose). All procedures complied with the standards for the care and use of experimental animals and approved by the Animal Ethics Committee of Khon Kaen University, Khon Kaen, Thailand (ACUC-KKU-17/2559).

After feeding the animals with a normal diet or HFFD for 10 weeks, the rats were divided into 6 groups with 6-8 animals each as follows: Group 1: Normal control group treated with distilled water, Group 2: Normal rats treated with ERB at a dose of $500 \mathrm{mg} / \mathrm{kg} \mathrm{BW/day,} \mathrm{Group} \mathrm{3:} \mathrm{HFFD}$ rats treated with distilled water, Groups 4 and 5: HFFD rats treated with ERB at doses of 250 and $500 \mathrm{mg} / \mathrm{kg}$ BW/day, and Group 6: HFFD rats treated with pioglitazone at dose of $10 \mathrm{mg} / \mathrm{kg} \mathrm{BW} /$ day. ERB was dissolved in distilled water. All treatments were administered orally daily to the animals for a further 4 weeks. During the additional 4 weeks of treatment, the animals continued to be fed HFFD for the HFFD groups. Fasting blood glucose (FBG) and oral glucose tolerance tests (OGTT) were determined before and after 4 weeks for all treatments. Serum insulin and lipid profiles were performed after treatments. The livers were collected at the end of this additional 4 weeks of each treatment for determining lipid content, peroxisome proliferator-activated receptor- $\alpha$ (PPAR- $\alpha$ ) expression, and histological examination.

\section{Determination of FBG, OGTT, lipid profile, and insulin}

Rats were fasted overnight (10-12 h), and blood samples were taken from the lateral tail vein to examine the FBG using a glucometer (Accucheck Advantage II; Roche, Germany). Then, the animals were orally administered glucose at $2.0 \mathrm{~g} / \mathrm{kg}$ [13] to evaluate OGTT. The blood glucose concentrations after glucose loading at 30,90 , and 120 min were determined. An area under the curve (AUC) of blood glucose-time (from 0 to $120 \mathrm{~min}$ ) was calculated. The fasting sera were also used to measure LDL, HDL, and TG using the Wako ${ }^{\circledR}$ diagnostics reagent (Wako, Japan), and insulin using the Rat/Mouse Insulin ELISA Kit (Millipore MA, USA). The assay was performed according to the manufacturer's protocol.
The Homeostasis Model Assessment of Insulin Resistance (HOMA-IR) is one index of insulin resistance which is calculated as follows: (Fasting insulin $[\mu \mathrm{IU} / \mathrm{mL}] \mathrm{X}$ fasting glucose $[\mathrm{mmol} / \mathrm{L}]] / 22.5$ [14]. Insulin $1 \mu \mathrm{IU} / \mathrm{mL}$ is equal to $6.945 \mathrm{pmol} / \mathrm{L}$.

\section{Determination of fat in liver and histological examination}

The hepatic TG was examined as described by Naowaboot [15]. Briefly, $50 \mathrm{mg}$ of liver was homogenized, and dissolved in $1 \mathrm{~mL}$ of isopropanol. Then, it was centrifuged at $10,000 \mathrm{rpm}$ for $15 \mathrm{~min}$ at $4^{\circ} \mathrm{C}$. The supernatant was collected. The TG contents of the analyzed liver samples were determined using the Wako Assay kit for TG. The amount of hepatic TG was expressed as $\mathrm{mg} / \mathrm{g}$ tissue.

A portion of liver was fixed in buffered neutral formalin $(10 \%)$ and the fixed tissue was processed for paraffin embedding. Tissue sections were stained with hematoxylin and eosin. Microscopic histological examinations of liver were performed.

\section{Determination of liver PPAR- $\alpha$ gene expression}

Total RNA was extracted from frozen liver tissues by TRIzol ${ }^{\circledR}$ reagents according to the manufacturer's instructions. $1 \mathrm{mg}$ of total RNA was then reverse transcribed to single-stranded cDNA using iScript reverse transcriptase (Bio-Rad, Hercules, CA). PCR were carried out using specific primers as follows: $\beta$-actin forward 5'-GGAGATTACTGCCCTGGCTCCTA-3' and $\beta$-actin reverse 5'-GACTCATCG TACTCCTGCTTGCTG-3', PPAR- $\alpha$ forward 5'-CTGGAGCCTAACGGACAGGTC- $3^{\prime}$ and PPAR- $\alpha$ reverse 5'-ACACTGCCGCAGCTAAGACTT-3'. The reaction was performed with SsoFast ${ }^{\mathrm{TM}}$ EvaGreen Supermix with low Rox (Bio-Rad, Hercules, CA) using Light Cycler 480II/384 (Roche Applied Science) under the following conditions: Denaturation at $95^{\circ} \mathrm{C}$ for $3 \mathrm{~min}$ and amplification by cycling 40 times at $95^{\circ} \mathrm{C}$ for $15 \mathrm{~s}$ and $60^{\circ} \mathrm{C}$ for $31 \mathrm{~s}$. The relative expression ratio of the target gene was calculated compared to the reference $\beta$-actin gene.

\section{Statistical analysis}

All results are presented as mean \pm SEM. The effects of ERB on blood glucose, OGTT, serum lipid profile, liver TG, serum insulin, and expression of PPAR- $\alpha$ were analyzed by analysis of variance followed by Student Newman-Keuls tests to show specific group differences. The level of significance was uniformly set at $\mathrm{p}<0.05$. Statistical analyses were carried out using Statistical Package for the Social Sciences version 19

\section{RESULTS}

\section{Characteristic of ERB}

Using a HPLC-DAD based assay, gallic acid, catechin, and isoquercetin were found at high amounts of 214.12, 212.60, and $201.64 \mathrm{mg} / \mathrm{kg}$, respectively. Tannic acid, rutin, quercetin, and apigenin were found at the amounts of $189.92,156.37,113.13$, and $6.12 \mathrm{mg} / \mathrm{kg}$, respectively. Eriodictyol, kaempferol, and hydroquinone were not detectable at a $5 \mathrm{mg} / \mathrm{kg}$ limit of detection.

\section{Effect of ERB on body weight gaining}

The body weights at the starting point of all experimental groups were similar (range 230-270 g). Feeding HFFD for the first 10 weeks did not affect the weight of the animals, however, continued feeding for a further 4 weeks caused a significant increase in body weight (Table 1 ). The HFFD rats that received ERB $(250$ or $500 \mathrm{mg} / \mathrm{kg}$ ) in the past 4 weeks had both lower body weights and growth rates (\% increase in body weight) as compared to the control HFFD group receiving distilled water (Table 1). Pioglitazone $(10 \mathrm{mg} / \mathrm{kg})$ did not show body weight reduction

\section{Effect of ERB on FBG and OGTT}

At the end of week 10 of HFFD feeding, the average of FBG of each group was in the range of $82-88 \mathrm{mg} / \mathrm{dL}$, which was not significantly different from normal diet fed rats. The OGTT results, however, showed that the AUC of blood glucose from 0 to 120 min (AUC showing the amount of glucose in blood from 0 min to $120 \mathrm{~min}$ ) of HFFD fed animals was significantly higher than that of normal control rats; this indicated an impairment of glucose tolerance and possibly an insulin resistant situation. Continued feeding with HFFD for a further 4 weeks caused 
a significantly high FBG and AUC as compared to normal diet fed rats (Table 2). This indicated that the hyperglycemia and insulin resistance occurred in rats fed with HFFD for 14 weeks. Interestingly, the HFFD rats treated with ERB (250 and $500 \mathrm{mg} / \mathrm{kg}$ ) or pioglitazone, had significantly lower FBG and AUC values than that of HFFD control rats (Table 2) indicating that ERB or pioglitazone could decrease FBG and improve OGTT in HFFD fed animals.

Effect of ERB on insulin secretion and HOMA-IR values

At the end of 14 weeks of HFFD feeding, the HFFD control rats had significant increases in serum insulin levels $(6.34 \pm 1.37 \mathrm{ng} / \mathrm{ml})$ and high HOMA-IR values $(43.63 \pm 9.63)$ as compared to normal control animals (serum insulin; $1.34 \pm 0.38 \mathrm{ng} / \mathrm{ml}$, HOMA-IR value; $5.78 \pm 1.47$ ) which indicated insulin resistance in HFFD control animals (Fig. 1). ERB administration at 250 and $500 \mathrm{mg} / \mathrm{kg}$ caused significant decreases in insulin secretion $(3.21 \pm 0.64$ and $2.60 \pm 0.76 \mathrm{ng} / \mathrm{ml})$ and HOMA-IR values $(18.69 \pm 3.75$ and $14.29 \pm 4.41)$. Pioglitazone also decreased both insulin and HOMA-IR levels (Fig. 1).

Table 1: Effect of ERB on body weight gaining of HFFD rats

\begin{tabular}{llll}
\hline Groups & \multicolumn{2}{l}{ Body weight $(\mathrm{g})$} & $\begin{array}{c}\text { \% increases of } \\
\text { body weight }\end{array}$ \\
\cline { 2 - 3 } & Week 10 & Week 14 & \\
\hline Normal control & $681.67 \pm 21.09$ & $693.33 \pm 19.54$ & $4.81 \pm 0.67$ \\
Normal+ERB 500 & $613.00 \pm 9.03$ & $663.00 \pm 11.73$ & $6.37 \pm 0.79$ \\
HFFD control & $694.50 \pm 22.04$ & $790.67 \pm 30.17^{*}$ & $12.22 \pm 0.90^{*}$ \\
HFFD+ERB 250 & $685.33 \pm 40.08$ & $694.83 \pm 38.03^{\#}$ & $5.18 \pm 1.84^{\#}$ \\
HFFD+ERB 500 & $638.67 \pm 15.75$ & $646.83 \pm 18.67^{\#}$ & $4.67 \pm 1.66^{\#}$ \\
HFFD+Pio 10 & $683.60 \pm 10.52$ & $806.20 \pm 17.73^{*}$ & $16.11 \pm 1.10^{*}$ \\
\hline
\end{tabular}

HFFD: High-fat-high-fructose diet, ERB 250 or 500: Ethanolic extract of rice bran at 250 or $500 \mathrm{mg} / \mathrm{kg}$, Pio 10: Pioglitazone at $10 \mathrm{mg} / \mathrm{kg},{ }^{*} \mathrm{p}<0.05$ as compared with normal control, $\# \mathrm{p}<0.05$ as compared with HFFD control
Effect of ERB on serum lipid profile and liver lipid content

HFFD feeding caused significant increases in serum cholesterol LDL and TG levels, and a significant decrease in HDL levels (Table 3) as compared to the normal control group which indicated a dyslipidemic situation in HFFD rats. Interestingly, the treatment with ERB at 250 and $500 \mathrm{mg} / \mathrm{kg}$ significantly decreased the levels of LDL and TG but had no effect on the levels of HDL. Pioglitazone decreased LDL and TG and also increased HDL levels (Table 3).

Determination of intrahepatic fat showed that the HFFD control group had a significant fat deposition in the liver $(107.20 \pm 3.59 \mathrm{mg} / \mathrm{g}$ tissue) as compared to the normal control group $(41.88 \pm 8.76 \mathrm{mg} / \mathrm{g}$ tissue), Fig. 2. The liver fat content of the ERB rats of the 250 and $500 \mathrm{mg} / \mathrm{kg}$ treated HFFD rats was significantly decreased $(75.60 \pm 8.02$ and $68.14 \pm 5.97 \mathrm{mg} / \mathrm{g}$ tissue) as compared to that of HFFD control group (Fig. 2) which indicated that ERB could decrease fat accumulation in livers of animals fed HFFD. ERB at $500 \mathrm{mg} / \mathrm{kg}$, however, did not affect fat accumulation in livers of normal rats. Pioglitazone also decreased fat deposition in liver $(47.03 \pm 3.47 \mathrm{mg} / \mathrm{g}$ tissue), Fig. 2 .

Histological examination of liver tissue was performed to confirm the effects of ERB on liver fat accumulation. It showed that hepatocytes of HFFD control rats prominently contained one or more large fat droplets and displaced the nuclei to eccentric positions (Fig. 3b), whereas the HFFD rats that received ERB or pioglitazone showed a mild deposition of fat (Fig. 3c, d, and e).

\section{Effect of ERB on PPAR- $\alpha$ expression in liver}

To examine the possible mechanisms of lipid-lowering activity and insulin resistance improvement activity of ERB, this study examined the effects of ERB on the expression of fatty acid beta-oxidation regulating the PPAR- $\alpha$ gene in liver cells using PCR technique. It was found that HFFD animals had lower expressions of PPAR- $\alpha$ mRNA (fold change of

Table 2: Effect of ERB on FBG and OGTT

\begin{tabular}{|c|c|c|c|c|}
\hline \multirow[t]{2}{*}{ Groups } & \multicolumn{2}{|c|}{ FBG (mg/dL) } & \multicolumn{2}{|c|}{ Area under curve (min.mg/dL) } \\
\hline & Week 10 & Week 14 & Week 10 & Week 14 \\
\hline Normal control & $77.27 \pm 3.48$ & $81.36 \pm 4.93$ & $13353 \pm 191$ & $13329 \pm 493$ \\
\hline Normal+ERB 500 & $80.25 \pm 3.12$ & $79.00 \pm 2.43$ & $14565 \pm 67$ & $13680 \pm 541$ \\
\hline HFFD control & $82.00 \pm 3.79$ & $110.80 \pm 1.69^{*}$ & $16920 \pm 662^{*}$ & $17933 \pm 327^{*}$ \\
\hline HFFD+ERB 250 & $87.67 \pm 2.30$ & $94.60 \pm 1.75^{\#}$ & $15925 \pm 590^{*}$ & $15606 \pm 385^{\#}$ \\
\hline HFFD+ERB 500 & $86.17 \pm 2.24$ & $92.67 \pm 3.80^{\#}$ & $15848 \pm 767 *$ & $15138 \pm 545^{\#}$ \\
\hline HFFD+Pio 10 & $88.20 \pm 3.36$ & $93.75 \pm 1.43^{\#}$ & $16410 \pm 620^{*}$ & $13335 \pm 672^{\#}$ \\
\hline
\end{tabular}

HFFD: High-fat-high-fructose diet, ERB 250 or 500: Ethanolic extract of rice bran at 250 or $500 \mathrm{mg} / \mathrm{kg}$, Pio 10 : Pioglitazone $10 \mathrm{mg} / \mathrm{kg}$, ${ }^{*} \mathrm{p}<0.05$ as compared with normal control, $" \mathrm{p}<0.05$ as compared with HFFD control, $\mathrm{n}=6-8$, FBG: Fasting blood glucose, OGTT: Oral glucose tolerance test

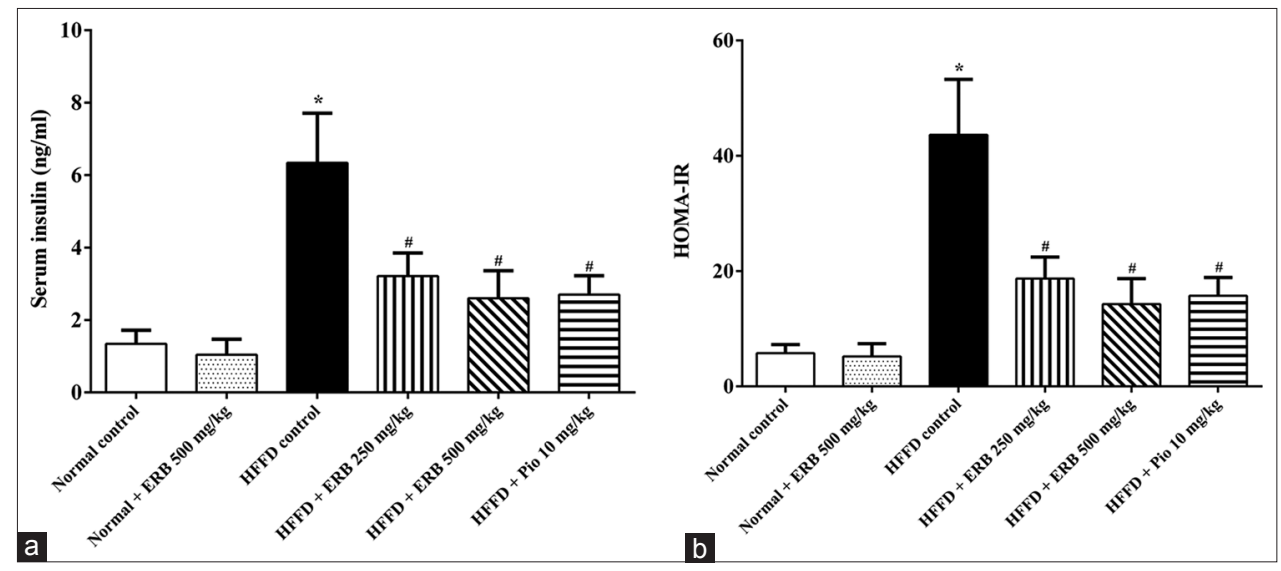

Fig. 1: Effect of ethanolic extract of rice bran (ERB) on serum insulin (a) and Homeostasis Model Assessment of Insulin Resistance (HOMA-IR) scores (b) treatment of the high-fat-high-fructose diet (HFFD) rats with ERB at 250 and $500 \mathrm{mg} / \mathrm{kg}$ could significantly decrease the serum insulin levels and HOMA-IR scores. ERB, Pioglitazone $10 \mathrm{mg} / \mathrm{kg}$, ${ }^{*} \mathbf{p}<0.05$ as compared with normal control, ${ }^{\#}<<0.05$ as compared with HFFD control 
$0.66 \pm 0.03$ ) than that of normal control animals (Fig. 4). Treatment with ERB at 250 and $500 \mathrm{mg} / \mathrm{kg}$ or pioglitazone caused a significant increase in PPAR- $\alpha$ expression as compared to HFFD controls (fold changes of $1.09 \pm 0.05,0.80 \pm 0.02$, and $0.81 \pm 0.07$, respectively), Fig. 4 .

\section{DISCUSSION}

After 14 weeks of HFFD feeding, the rats had an insulin resistant situation; impaired OGTT, hyperinsulinemia, high FBG, high LDL, and TG levels, together with an accumulation of fat in the livers. These results showed that ERB could ameliorate all those metabolic changes in HFFD-induced insulin resistant rats and ERB did not affect glucose and lipid metabolism in normal rats.

A HFFD has been used to induce insulin resistance in animals [16]. A high-fat diet has been known to induce insulin resistance in both

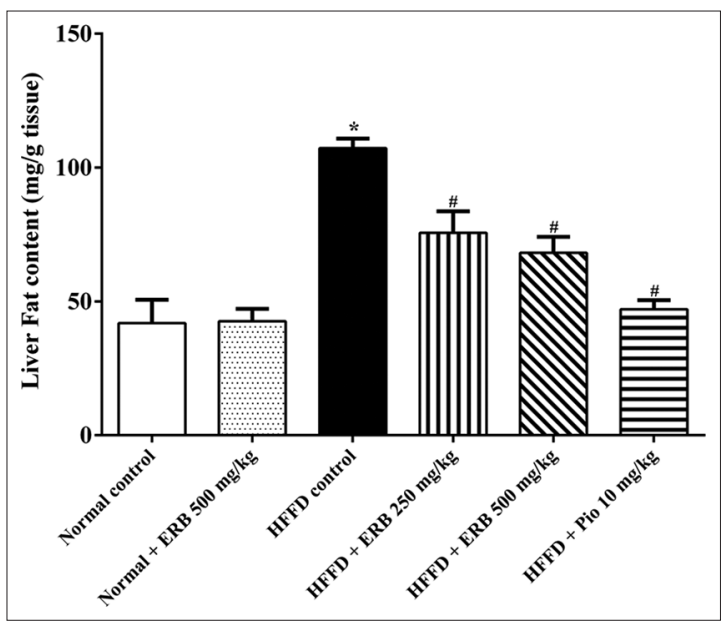

Fig. 2: Effects of ethanolic extract of rice bran (ERB) on hepatic fat accumulation. ERB at 250 and $500 \mathrm{mg} / \mathrm{kg}$ could significantly decrease the fat accumulation in liver. Pioglitazone $10 \mathrm{mg} / \mathrm{kg}$, ${ }^{*} \mathbf{p}<0.05$ as compared with normal control, ${ }^{\#} \mathbf{p}<0.05$ as compared with high-fat-high-fructose diet contro

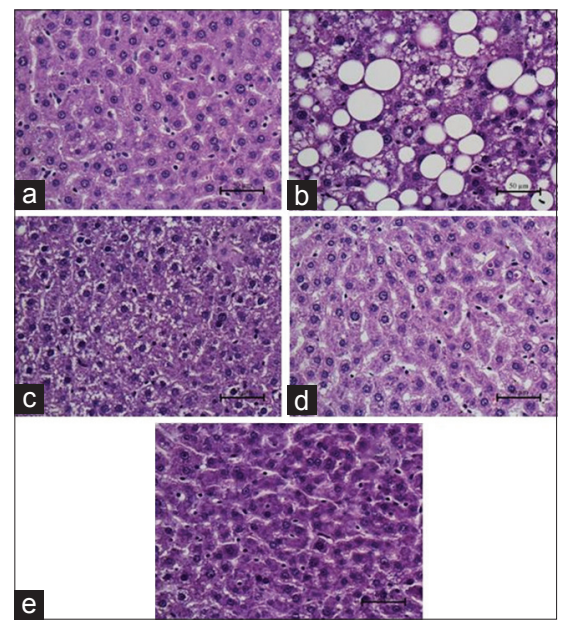

Fig. 3: Histological examination of liver tissue of (a) normal control, (b) high-fat-high-fructose diet (HFFD), (c, d) HFFD treated with ethanolic extract of rice bran (ERB) at $250 \mathrm{mg} / \mathrm{kg}$ and $500 \mathrm{mg} / \mathrm{kg}$; and (e) pioglitazone groups using light microscopy with a magnification of 40X. HFFD control rats contained one or more large fat droplets that prominently displaced the nucleus

to an eccentric position, whereas the HFFD rats that received ethanolic ERB or pioglitazone (Pio) showed a mild deposition of fat Pio $10 \mathrm{mg} / \mathrm{kg}$ humans and animal models. Excess calorie intake can theoretically be stored in adipose tissue, but as the inflammatory process increases and insulin resistance develops in the fat cells the ability to safely store excess fat is compromised. One of the consequences of insulin resistance in the adipose tissue is that excess fat is released into the bloodstream and is sequestered by other organs such as liver and skeletal muscles causing cellular lipotoxicity and finally insulin resistance in those organs [17]. It has been proposed that the lipid-overload causes a buildup of diacylglycerides or free fatty acids or ceramides; these substances inhibit the intracellular signaling of insulin through serine/threonine phosphorylation of insulin receptor substrate-1 [18]. Fructose consumption has also been shown to enhance the risk of metabolic syndrome, including obesity, insulin resistance, and Type 2 D. Fructose is predominantly metabolized in the liver where it enhances de novo lipogenesis [5] probably resulting in enhanced insulin resistance.

Interestingly, for glucose metabolism, ERB decreased FBG and improved OGTT, and for lipid metabolism, ERB decreased LDL and TG levels in HFFD rats. In addition, ERB decreased hyperinsulinemia and the HOMA-IR score. All these beneficial changes indicate that ethanolic extract of Tubtim-chumphae rice bran could improve insulin resistance and may have antidiabetic activity. The obtained results correspond to an in vitro experiment reported by Boue [19]. They have reported an in vitro effect of ethanolic extract of colored rice bran cultivated in Brazil on glucose levels and insulin activity; inhibiting $\alpha$-glucosidase activity, stimulating glucose uptake and increasing expression of Glucose transporter type (GLUT)1 and GLUT4 mRNA in 3T3-L1 adipocytes. The

Table 3: Effect of ERB on serum lipid profile in HFFD rats

\begin{tabular}{llll}
\hline Groups & \multicolumn{2}{l}{ Lipid profile $(\mathbf{m g} / \mathbf{d L})$} \\
\cline { 2 - 4 } & LDL & HDL & TG \\
\hline Normal control & $11.92 \pm 1.21$ & $31.67 \pm 1.79$ & $74.00 \pm 10.46$ \\
Normal+ERB500 & $11.43 \pm 1.24$ & $36.70 \pm 1.87$ & $78.00 \pm 10.62$ \\
HFFD control & $22.57 \pm 3.40^{*}$ & $21.55 \pm 2.38^{*}$ & $104.75 \pm 8.38^{*}$ \\
HFFD+ERB 250 & $14.64 \pm 1.06^{\#}$ & $27.82 \pm 3.62$ & $49.50 \pm 6.94^{\#}$ \\
HFFD+ERB 500 & $11.31 \pm 1.03^{\#}$ & $29.62 \pm 5.22$ & $39.00 \pm 2.12^{\#}$ \\
HFFD+Pio 10 & $13.43 \pm 1.18^{\#}$ & $38.64 \pm 5.46^{\#}$ & $57.60 \pm 7.96^{\#}$ \\
\hline
\end{tabular}

HFFD: High-fat-high-fructose diet, ERB 250 or 500: Ethanolic extract of rice bran at 250 or $500 \mathrm{mg} / \mathrm{kg}$, Pio 10: Pioglitazone $10 \mathrm{mg} / \mathrm{kg}$, ${ }^{*} \mathrm{p}<0.05$ as compared with normal control, ${ }^{\#} \mathrm{p}<0.05$ as compared with HFFD control, $\mathrm{n}=6-8$, LDL: Low-density lipoprotein, HDL: High-density lipoprotein, TG: Triglyceride

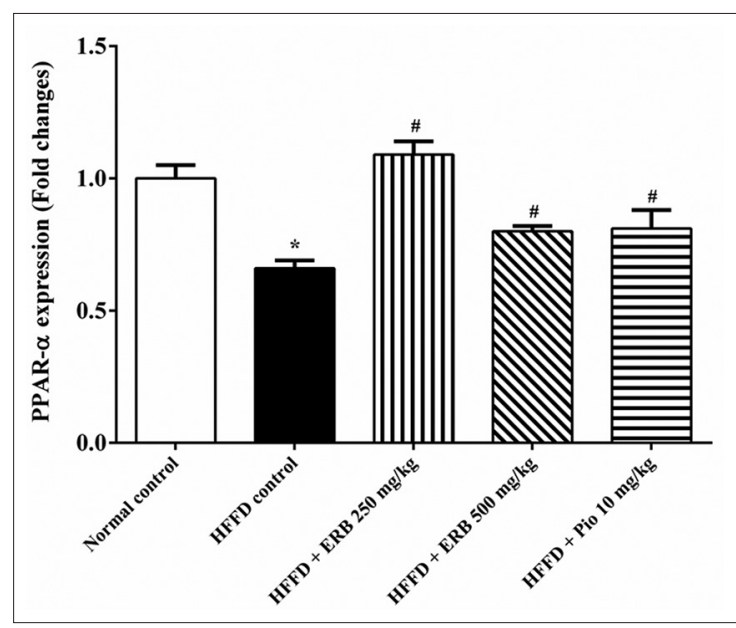

Fig. 4: Effects of ethanolic extract of rice bran (ERB) on liver peroxisome proliferator-activated receptor- $\alpha$ (PPAR- $\alpha$ ) expression in high-fat-high-fructose diet (HFFD) rats. ERB at 250 and $500 \mathrm{mg} / \mathrm{kg}$ could significantly increase the PPAR- $\alpha$ expression in liver cells of HFFD rats. Pioglitazone $10 \mathrm{mg} / \mathrm{kg}$, ${ }^{*} \mathbf{p}<0.05$ as compared with normal controls, ${ }^{*} \mathbf{p}<0.05$ as compared with HFFD contro 
mechanism of anti-diabetic and insulin resistance improving activities of ERB will be further investigated in Type $2 \mathrm{D}$ animals.

Fat and fructose overconsumption has also been reported to cause intrahepatic fat accumulation promoting the development of NAFLD that is linked with metabolic disorders such as obesity and Type 2 D [5]. Liver lipid accumulation or steatosis is the early stage of NAFLD which can occur from the diet, from de novo lipogenesis or lipids released from adipose tissue. It is a phenomenon that develops rapidly when rats are fed a high-fat diet, but the accumulation does not increase linearly over time [1]. In the case of a chronic high-fat diet; however, the concurrent oxidative stress, inflammatory processes, mitochondrial dysfunction, and insulin resistance may finally cause the hepatocyte injuries leading to steatohepatitis or cirrhosis which is the second stage of NAFLD. This study also found lipid accumulation in the livers of HFFD rats as well. Interestingly, the liver lipid content which was examined both by biochemical and histological Methods,. the results of these two methods were consistent showing that ERB treatment could decrease the accumulation of fat in the liver of HFFD rats. At the present state of knowledge, our report appears to be the first report demonstrating an in vivo anti-insulin resistance and intrahepatic fat decreasing activities of the ethanolic extract of defatted colored rice bran in insulin-resistant animals.

PPAR- $\alpha$ is a ligand-activated transcription factor regulating genes in controlling fat metabolism. Many PPAR- $\alpha$ target genes are involved in fatty acid metabolism including genes involved in mitochondrial $\beta$-oxidation, peroxisomal $\beta$-oxidation, fatty acid uptake and binding, and lipoprotein assembly, and transport in tissues such as muscle, heart, and liver [20]. PPAR- $\alpha$ activation has been reported to improve steatosis, inflammation, and fibrosis in animal models of non-alcoholic fatty liver disease [21]. As fatty acids or diacylglycerol or ceramides all are proposed to cause insulin resistance, and PPAR- $\alpha$ is transcription factor regulating gene in controlling fat metabolism, therefore further investigation of the effects of ERB on PPAR- $\alpha$ gene expression in liver was pursued. Interestingly, it was found that ERB could noticeably increase the expression of PPAR- $\alpha$. Thus, it can be proposed that one of the possible mechanisms of action of ERB is that ERB increases PPAR- $\alpha$ expression resulting in a decrease of insulin resistance, LDL, and TG blood levels as well as fat accumulation in the liver. In the aspect of PPAR- $\alpha$ in regulating the body weight, it has been shown that PPAR- $\alpha$ agonists could reduce body weight and adiposity in animal models [22]. This probably may explain why the HFFD rats receiving ERB had lower body weights than those of control HFFD rats.

Pioglitazone is known to improve insulin sensitivity, glycemic control, dyslipidemia, hypertension, and microalbuminuria in patients with Type 2 D. Pioglitazone selectively stimulates the PPAR- $\gamma$ and to a lesser extent PPAR- $\alpha$ [23]. It modulates the transcription of the genes involved in the control of glucose and lipid metabolism in the muscle, adipose tissue, and the liver. As a result, pioglitazone reduces insulin resistance in the liver and peripheral tissues, decreases gluconeogenesis in the liver, and reduces the levels of glucose and glycated hemoglobin in the bloodstream. This current study employed pioglitazone treatment as a positive control group in which pioglitazone showed effects as expected.

\section{CONCLUSIONS}

HFFD feeding for 14 weeks was found to cause insulin resistance and steatosis in rats. At the present state of knowledge, this is the first report demonstrated that the treatment with an ethanolic extract of colored rice bran can decrease insulin resistance and fat accumulation in liver through stimulation of PPAR- $\alpha$ expression in HFFD rats. Thus, of ERB Tubtim-chumphae may possibly be used as neutraceutical for the metabolic syndrome and Type 2 diabetic patients.

\section{ACKNOWLEDGMENT}

This work was supported by the Faculty of Medicine (grant number IN61216) and Cardiovascular Research Group, Khon Kaen University, Thailand, and by Chumphae Rice Research Center, Khon Kaen, Thailand.
Jiraprapa Ponglong is a Master of Science in Pharmacology student, Faculty of Medicine, Khon Kaen University, Thailand. We would like to acknowledge Prof. James Will, University of Wisconsin-Madison for editing the MS through Publication Clinic KKU, Thailand.

\section{AUTHORS' CONTRIBUTIONS}

We declare that this work was done by the authors named in this article. Patchareewan Pannangpetch conceived and designed the experiment, analyzed data, and edited the manuscript. Jiraprapa Ponglong performed the experiment, analyzed data, and wrote the manuscript. Laddawan Senggunprai and Panot Tungsutjarit analyzed data. Ronnachai Changsri and Tunvaraporn Proongkhong provided Tubtim-chumphae rice bran.

\section{CONFLICTS OF INTEREST}

The authors have no conflicts of financial or personal interests with any other organizations or people.

\section{REFERENCES}

1. Gauthier MS, Favier R, Lavoie JM. Time course of the development of non-alcoholic hepatic steatosis in response to high-fat diet-induced obesity in rats. Br J Nutr 2006;95:273-81.

2. Roberts CK, Hevener AL, Barnard RJ. Metabolic syndrome and insulin resistance: Underlying causes and modification by exercise training. Compr Physiol 2013;3:1-58.

3. Grundy SM. Metabolic syndrome update. Trends Cardiovasc Med 2016;26:364-73

4. Fouret G, Gaillet S, Lecomte J, Bonafos B, Djohan F, Barea B, et al. 20-week follow-up of hepatic steatosis installation and liver mitochondrial structure and activity and their interrelation in rats fed a high-fat-high-fructose diet. Br J Nutr 2018;119:368-80.

5. Dekker MJ, Su Q, Baker C, Rutledge AC, Adeli K. Fructose: A highly lipogenic nutrient implicated in insulin resistance, hepatic steatosis, and the metabolic syndrome. Am J Physiol Endocrinol Metab 2010;299:E685-94

6. Vichit W, Saewan N. Antioxidant activities and cytotoxicity of thai pigmented rice. Int J Pharm Pharm Sci 2015;7:329-34.

7. Settharaksa S, Madaka F, Charkree K, Charoenchai L. The study of anti-inflammatory and antioxidant activity in cold press rice bran oil from rice in Thailand. Int J Pharm Pharm Sci 2014;6:428-31.

8. Sukrasno S, Tuty S, Fidrianny I. Antioxidant evaluation and phytochemical content of various rice bran extracts of three varieties rice from Semarang, central Java, Indonesia. Asian J Pharm Clin Res 2017; 10:377-82.

9. Sabir A, Rafi M, Darusman LK. Discrimination of red and white rice bran from indonesia using HPLC fingerprint analysis combined with chemometrics. Food Chem 2017;221:1717-22.

10. Niu Y, Gao B, Slavin M, Zhang X, Yang F, Bao J, et al. Phytochemical compositions, and antioxidant and anti-inflammatory properties of twenty-two red rice samples grown in Zhejiang. LWT Food Sci Technol 2013;54:521-7.

11. Boonloh K, Kukongviriyapan V, Kongyingyoes B, Kukongviriyapan U, Thawornchinsombut S, Pannangpetch $\mathrm{P}$, et al. Rice bran protein hydrolysates improve insulin resistance and decrease pro-inflammatory cytokine gene expression in rats fed a high carbohydrate-high fat diet. Nutrients 2015;7:6313-29.

12. Peñarrieta JM, Alvarado JA, Akesson B, Bergenståhl B. Total antioxidant capacity and content of flavonoids and other phenolic compounds in canihua (Chenopodium pallidicaule): An andean pseudocereal. Mol Nutr Food Res 2008;52:708-17.

13. Mungkhunthod S, Senggunprai L, Tangsucharit P, Sripui J, Kukongviriyapan U, Pannangpetch P. Antidesma thwaitesianum pomace extract improves insulin sensitivity via upregulation of PPAR- $\gamma$ in high fat diet/streptozotocin-induced Type 2 diabetic rats. Asia Pac J Sci Technol 2016;21:63-76.

14. Matthews DR, Hosker JP, Rudenski AS, Naylor BA, Treacher DF, Turner RC, et al. Homeostasis model assessment: Insulin resistance and beta-cell function from fasting plasma glucose and insulin concentrations in man. Diabetologia 1985;28:412-9.

15. Naowaboot J, Wannasiri S. Anti-lipogenic effect of Senna alata leaf extract in high-fat diet-induced obese mice. Asian Pac J Trop Biomed 2016;6:232-8

16. Couturier K, Qin B, Batandier C, Awada M, Hininger-Favier I, Canini F, et al. Cinnamon increases liver glycogen in an animal model of insulin 
resistance. Metabolism 2011;60:1590-7.

17. Sears B, Perry M. The role of fatty acids in insulin resistance. Lipids Health Dis 2015;14:121.

18. Shulman GI. Cellular mechanisms of insulin resistance. J Clin Invest 2000;106:171-6.

19. Boue SM, Daigle KW, Chen MH, Cao H, Heiman ML. Antidiabetic potential of purple and red rice (Oryza sativa L.) bran extracts. J Agric Food Chem 2016;64:5345-53.

20. Hashimoto T, Cook WS, Qi C, Yeldandi AV, Reddy JK, Rao MS, et al. Defect in peroxisome proliferator-activated receptor alpha-inducible fatty acid oxidation determines the severity of hepatic steatosis in response to fasting. J Biol Chem 2000;275:28918-28.

21. Pawlak M, Lefebvre P, Staels B. Molecular mechanism of PPAR $\alpha$ action and its impact on lipid metabolism, inflammation and fibrosis in non-alcoholic fatty liver disease. J Hepatol 2015;62:720-33.

22. Guerre-Millo M, Gervois P, Raspé E, Madsen L, Poulain P, Derudas B, et al. Peroxisome proliferator-activated receptor alpha activators improve insulin sensitivity and reduce adiposity. J Biol Chem 2000;275:16638-42.

23. Smith U. Pioglitazone: Mechanism of action. Int $\mathrm{J}$ Clin Pract Suppl 2001;121:13-8. 